Managementforschung 6 



\section{Managementforschung 6}

Wissensmanagement

Herausgegeben von

Georg Schreyögg und Peter Conrad

$\mathrm{W}$
$\mathrm{GE}$
$\mathrm{G}$

Walter de Gruyter · Berlin · New York 1996 
Prof. Dr. Georg Schreyögg, Institut für Management, Fachbereich Wirtschaftswissenschaft, Freie Universität Berlin, 14195 Berlin

Prof. Dr. Peter Conrad,

Universität der Bundeswehr Hamburg, 22039 Hamburg

Das Buch enthält 29 Abbildungen und 8 Tabellen

@ Gedruckt auf säurefreiem Papier, das die US-ANSI-Norm über Haltbarkeit erfüllt

Die Deutsche Bibliothek - CIP-Einheitsaufnahme

Managementforschung ... - Berlin ; New York : de Gruyter.

Erscheint jährlich. - Aufnahme nach 1 (1991)

6. Wissensmanagement. -1996

Wissensmanagement : [enthält 8 Tabellen] / hrsg. von Georg

Schreyögg und Peter Conrad. - Berlin ; New York : de Gruyter, 1996

(Managementforschung ... ; 6)

ISBN 3-11-014999-0

NE: Schreyögg, Georg [Hrsg.]

(C) Copyright 1996 by Walter de Gruyter \& Co., D-10785 Berlin

Dieses Werk einschließlich aller seiner Teile ist urheberrechtlich geschützt. Jede Verwertung außerhalb der engen Grenzen des Urheberrechtsgesetzes ist ohne Zustimmung des Verlages unzulässig und strafbar. Das gilt insbesondere für Vervielfältigungen, Übersetzungen, Mikroverfilmungen und die Einspeicherung und Verarbeitung in elektronischen Systemen. Printed in Germany.

Druck: WB-Druck GmbH, Rieden am Forggensee. - Buchbinderische Verarbeitung:

Dieter Mikolai GmbH, Berlin. - Einbandgestaltung: Johannes Rother, Berlin. 